\title{
Given Enough Eyeballs, All Crimes are Shallow - The Organizing of Citizen Collaboration to Solve an Online Detective Story
}

\author{
Björn Remneland Wikhamn ${ }^{1 *}$, Jan Ljungberg ${ }^{2}$, Bertil Rolandsson ${ }^{3}$, Magnus Bergquist ${ }^{4}$
}

\begin{abstract}
This paper theorizes about the organizing of online citizen collaboration. The setting is an Internet forum where people started their own investigations about a crime of animal cruelty. The concepts of commons-based peer production and generativity are utilized to analyse the complex organizing mechanisms of voluntaristic online collaboration in practice. Three general functions are introduced - operational, managerial, and noise - which are intertwined and together make up important basis for organizing generativity.
\end{abstract}

Keywords: Commons-based peer production; citizen collaboration.

Submitted: August 29 2 th 2018 / Approved: May $2^{\text {nd }}, 2019$

\section{Introduction}

New distributed organizational forms have emerged in the wake of the Internet and mobile information technologies. Common to these modes of organizing is the collaboration across organizational and social boundaries (Benkler, 2006), facilitated by digital infrastructure (Zittrain, 2008; Baym, 2010) and a participatory (digital) culture (Jenkins, 2006). The term Commons-Based Peer Production (CBPP) aims to describe more fully such distributed initiatives (Benkler, 2006; 2015; Benkler \& Nissenbaum, 2006) and to challenge the governance modes of production found in hierarchies, markets or networks. Illustrative examples often linked to CBPP are, for instance, communitymanaged open source software projects (O’Mahony \& Ferraro, 2007; Hertel et al., 2003) and the Wikipedia (Loveland \& Reagle, 2013). By making software code and encyclopedia content a common shared property instead of a protected proprietary asset, these phenomena have radically reshaped the software and encyclopedia industries.

In recent years, examples have also emerged where peer production has taken a crucial role in activities linked to Governmental and Public authorities, such as in areas of e-democracy (Wright, 2012), collaborative public management (Goldsmith \& Eggers, 2005) and in citizen engagement e.g., for election campaigns (Cogburn \& Espinoza-Vasquez, 2011), in protest manifestations (Mercea, 2012) or in crisis management of natural disasters (Yates \& Paquette, 2011). We will in this paper call these ventures online citizen collaborations, due to their attention to topics of societal importance, their participation inclusiveness, and their bottom-up organizing processes. Some of these projects utilize more organization-centric approaches, where one focal actor (e.g., a Governmental agency, a public organization or a non-profit organization) is managing the mobilization and engagement of citizens to participate in certain predefined tasks or problem-solving work. However, an increasing number of citizen collaborations are also exemplifying more 'pure' CBPPs, where people set their agendas and self-allocate and self-organize themselves in voluntaristic and informal manners, e.g., in order to search for missing people or in solving crimes (c.f. Goldsmith, 2010).
This paper reports a study about such a CBPP citizen collaboration. The setting is an Internet forum, which we will call The Space, where people started their investigations about a crime of animal cruelty. So far, there is limited research about distributed public organizing in taking on such civic tasks, and more specifically on how these publicly distributed ventures are organized in practice. In order to investigate various forms of collective problem-solving processes, studies have commonly been inspired by the literature on open source, user innovation, and online communities, highlighting areas such as about motivational forces (e.g., Hertel et al., 2003), governance modes (e.g., O'Mahony \& Ferraro, 2007) and participatory IT architectures (e.g., West \& O'Mahony, 2008). Most studies of open and distributed innovation are technology-driven and focusing on partly commercial projects. Studies that examine online collaborations focusing on broader societal interests were amateurs voluntarily participate in the creative process, are still rare. Hence, we suggest that studying the organizing mechanisms of CBPP in online collaborations (in this case anonymous crime solvers on The Space) will add knowledge about and their possibilities and challenges in contemporary society. The research question is: What mechanisms enable the organizing of online citizen collaborations in order to solve crimes? We will take our theoretical departure in CBPP, and analyze how such organizing is done in practice and also discuss some critical implications this mode of production have on society at large. We concur with Kreiss et al. (2011) in that peer production is too often excessively celebrated for its positive potentials and seldom challenged for its negative aspects. For instance, Kreiss et al. (2011) argue that peer production transforms the social dynamics and governance from State laws and regulations, constituted on fairness, accountability, and inclusivity, to more blurry, ad hoc and anonymous meritocratic relations. By examining a case of citizen collaboration, these societal challenges in organizing dynamics will become more visible, as it will problematize the discussion about which tasks peer production can and should overtake from the State and Governmental actors, for the good of the civil society.

1) Department of Business Administration, School of Business, Economics and Law, University of Gothenburg, Sweden.

2) Department of Applied IT, University of Gothenburg, Sweden.

3) Department for Sociology and Work Science, University of Gothenburg, Sweden.

4) School of Information Technology, Halmstad University, Sweden.

*Corresponding author: Bjorn.Wikhamn@handels.gu.se

ISSN: 0718-2724. (http://jotmi.org)

Journal of Technology Management \& Innovation (c) Universidad Alberto Hurtado, Facultad de Economía y Negocios.

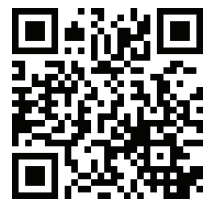

59 
The article is structured as follows. First we relate the paper to research on open and distributed innovation. Next, we specifically examine the theoretical notions of commons-based peer production (Benkler, 2006) and generativity (Zittrain, 2008; Remneland Wikhamn et al., 2011) as the basis for the theoretical perspective that will be used to analyze the empirical case. Third, the implications of the study are examined, in line with how theories relate to the empirical case and how studying online collaborations can provide further elaboration on the selected theoretical concepts. The article ends with some final conclusions.

\section{Commons-based peer production and generativity}

Within the realm of distributed organizational forms, Benkler (2006) introduces the notion Commons-Based Peer Production (CBPP). He describes it as:

[R]adically decentralized, collaborative, and nonproprietary; based on sharing resources and outputs among widely distributed, loosely connected individuals who cooperate with each other without relying on either market signals or managerial commands (Benkler, 2006, p. 60)

In this production mode, no single actor 'owns' the outcome or manages its direction and the process is highly decentralized, providing free and voluntaristic opportunities for action. While open innovation and crowdsourcing add to a long trend in industrial innovation management where firms gain knowledge from external resources and connect to other actors in consortia or networks (Mowery, 2009), CBPP is proposed to be a new modality of organizing production, fully distributed and without governance through traditional hierarchies or markets (Benkler, 2006). As such, it differs from firm-centric open innovation initiatives, which do not separate ownership from governance and which could be considered to be a relatively controlled way of opening up. CBPP, on the other hand, is an organizational form where the initiatives to a large extent lie outside of the firm boundaries. It also differs from crowdsourcing where the tasks are often regimented and pre-specified by the task owner. However, CBPP resemblances with much open innovation- and crowdsourcing activities in its dependency on digitally networked environments provided by the Internet and web-based services for leveraging the distributed resources. To this end, social media and social networking sites (SNS) have become vital resources.

Benkler and Nissenbaum (2006) further detail that CBPP relations regularly exhibit three structural attributes: 1) modularity (i.e., that the commons is divisible into independent components), 2) fine granularity (i.e., that the size of these modules can be rather small), and 3) low-cost integration (i.e., effective mechanisms for integrating the modules into a whole). If these characteristics are in place, it opens up the possibilities for a large pool of contributors to engage in production both incrementally and asynchronously. Benkler (2013) has recently also defined peer production organizing in that it combines three core characteristics; 1) the decentralization of both conception and execution of problems and solutions, 2) the harnessing of diverse motivations and 3) the separation of governance and management from property and contract. Furthermore, Benkler (2013) argues that CBPP is best suited for tasks where the degree of uncertainty in the project is high, where the knowledge required is tacit, creative and intuitive and where the capital cost of execution is low or distributed.

A related notion to CBPP and its additive production is that of generativity (Zittrain, 2008; Remneland Wikhamn et al., 2011). Similar to Benkler (2006), Zittrain (2008) takes his start from the technological architecture of the Internet and of traditional PC infrastructure. He explains generativity as "a system's capacity to produce unanticipated change through unfiltered contributions from broad and varied audiences" (Zittrain, 2008, p. 70). He also argues that "how much the system facilitates audience contribution is a function of both technological design and social behavior" (Zittrain, 2008, p. 71). In that sense, generativity encompasses the technology's or website's affordances (Leonardi, 2011), i.e., the designed properties for generating human agency and making the members of the network to relate to each other. Zittrain (2008) argues that a generative system is based on five principal factors; 1) leverage (i.e., the degree that the technology provide help for a set of possible tasks), 2) adaptability (i.e., the level of flexibility that the technology has in performing a range of different tasks), 3) ease of mastery (i.e., the technology's user-friendliness to newcomers and a wide audience), 4) accessibility (i.e., the technology's availability to ordinary users), and 5) transferability (i.e., how transferable any changes are to other participants). Concepts such as open innovation (Chesbrough, 2003) and open source (Hertel et al., 2003) are, as mentioned earlier, strongly associated with 'openness' as vehicles for value creation, but in line with Zittrain's argumentation it is possible to suggest that it is instead the level of generativity that facilitates exponential value growth in large-scale collaborative projects (Remneland Wikhamn et al., 2011).

We argue that generativity is connected to CBPP in the sense that the former can be seen as a further explanation of the mechanisms of value creation within distributed projects. Benkler (2013) highlights the need to protect users' 'freedom to operate' in the governance of CBPP, since "it is precisely the lack of need of actors to seek permission or await direction before acting that allows peer production to avoid the information and diversity losses associated with price-cleared and hierarchical systems" (Benkler, 2013, p. 110). In other words, successful CBPP ventures generate increasing returns to scale up the value creation and harness people's creative contributions while still adhering to diverse and multiple individual motivations for engagement. The outcome of such tinkering and remixing projects can be, for instance, labeled as mashups (Weiss \& Gangadharan, 2010) or bricolage (Baker \& Nelson, 2005), although CBPP is often a continuous iterative process where contributions are fed back to the community. The strength of these collaborative enterprises lies in the diversity of contributors' knowledge, resources, and associations, but also in the possibilities that these different contributors can elaborate on the works of the others. When this happens on a large scale, strong positive feedback loops can become mobilized which make the outcome exponentially improved. 
We will use CBPP and generativity as theoretical constructs to analyze the empirical case of voluntaristic online collaboration to solve crimes. We show that these mechanisms have potential benefits that go beyond the resources and legal constraints of the police force, but that it also opens up several challenges and problematic issues related to e.g., ethics, personal integrity, and public laws.

\section{Methodology}

\section{Research design}

A case study approach (Stake, 2000) is utilized to discuss CBPP and generativity in citizen collaborations for solving crimes on Internet forums. Case study research is a well-established method, particularly suitable when analyzing new and explorative research areas. Case studies can provide valuable illustrations of dynamic processes (Siggelkow, 2007) and act as a basis for theoretical, in-depth insights about a particular topic or concern (Stake, 2000). The gathering of empirical data for the paper was inspired by netnographic methodologies (Kozinets, 2010) in which we in a structured way have downloaded and analyzed written posts from a conversation on the Internet forum The Space, as well as news articles related to the specific case of the pet killer mystery.

Walther (2002) suggests that when Internet resources are more frequently used by researchers in social science research, it raises two concerns; 1) how these new research methods may affect ethical protection of human subjects, and 2) the validity of the collected data. Regarding the first issue, we have deliberately used a medium, an open online forum, where the participants are fully aware of that their posts are publicly accessible. We also made our best to make the case and its participants anonymous and since all quotes have been translated to a different language, the texts are not traceable online. Regarding the second issue, we have used an inductive approach to the analysis of qualitative data, and the analysis of these texts is explained further down.

\section{The setting: The Space}

The Space is a highly trafficked Internet forum, with two million unique visitors per week. The community includes almost 1 million members who publish about 20000 posts per day. The Space has roots from the early 80 s when it started as a printed punk magazine. In the 90 s it was transformed to an underground magazine with the aim to write about topics which nobody else writes about, such as drugs, death, deviant behavior and various forms of crime. In 1995 it was launched on the Internet, with a large archive of URL-links to morally questionable websites (this was before search engines, such as Alta Vista and Google had emerged). A few years later, The Space started a free web hotel, hosting only websites that had been closed down due to moral reasons. This web hosting immensely increased the diversity of the community to include members such as outlaw bikers, Nazis, anarchists, hackers, antifascists and Satanists. As such, it emerged as a free zone for people with provocative opinions and who would like to discuss these topics anonymously or spread information about various, often abnormal or politically incorrect, information to the community. During the years, the website has faced many controversies, in the form of public critique, accusations, and even legal impeachments. The community has increased exponentially, and the growth was escalated when the forum also opened to non-registered viewers. The critique toward the activities on the site remained, but also more positive stories started to circulate where the free speech and transparency showed its benefits. In recent years, The Space has even received prizes for the investigative journalism taken place on the forum.

\section{Data collection and data analysis}

One whole conversation thread, including more than 8000 individual posts (including e.g., post id, post time, content, username, and user registration date), was downloaded from The Space in the summer of 2014, using a simple script. The posts were published by users between the spring and fall of 2013, during the time that the crimesolving work took place. Added to this empirical material were also 50 news articles reporting about the case.

We imported the posts from the forum into Excel and to a CDA program for further analysis. The empirical data was coded and categorized into analytical themes (Strauss \& Corbin, 1990) with the help of these computer programs. During the coding, we assigned codes, classifications, names, and labels to texts that we perceived as significant for the case in the sense that they include information about the organizing of the solving process. This work also included the formation of a timeline for key milestones in the investigation process and an analysis of the different roles and functions of different key users over time. In the data analysis we were inspired by the grounded theory framework (Strauss \& Corbin, 1990), where selective coding was used to progressively move constructs to higher and higher levels of abstraction. The analysis work has been conducted in collaboration between the members of the research team in order to enhance sensemaking and critical reflection.

\section{The online citizen detectives and the pet killing mystery}

The case that this paper will analyze happened in 2013. Within a town district of a middle-sized city, dead (more or less slaughtered) pets turned up, one by one, on various locations. At first, the police were shown little interest in the matter, perceiving it as a minor crime. Local citizens such as the pet owners and their friends, however, started to act in order to identify who the offender was. They also utilized social media, such as The Space and Facebook, to organize their work. The involvement of participants in this search for the perpetrator increased in number as well as commitment, as the killings continued and traditional news media began to report about the case. Now, the police also started to put resources on finding this perpetrator, as well as to inform the local citizens and the media about the process. Groups were patrolling the streets at night, demonstrations were organized, and civilians and organizations offered monetary rewards for information leading to a capture. On The Space, several loosely organized groups worked more actively to solve the identity of the offender. Eventually, the police arrested an under-aged boy for the crimes, and he was later convicted and sentenced to forensic psychiatric care. For the public, the spokespersons from the police highlighted the 
crucial role that the groups on The Space have had during the process, stating that they were crucial for the capture of the offender. "These people were of great help, and we are very grateful that they took their time to assist in the process," said one of the police investigators to the press afterward.

In the aftermath, representatives from a loosely organized group on The Space started to take credit for being the ones who led the police to the right person. They also revealed a bit of the process and activities behind the scene, which they claimed eventually led to the identification of the offender. The killing of pets took place throughout several months, and it turned out that the convicted boy was also an active follower of the posts on The Space. When the groups realized this, they aimed to gain that user's friendship and trust, in order for him to reveal his real identity. In the news, one of them stated;

Several of us have worked on The Space in other cases, but then it has often been about a crime that already has been made. When it happens in real time, and can explode again anytime, or even strike on a human being, then it becomes extra intensive, and one does not want to feel afterward that he killed a woman, and we could have worked harder.

To solve the crime, people organized themselves both in the public forum, and through other means, such as writing private PMs or email, using other websites, and meeting in real life.

In this paper, we will analyze how the organizing of crime solving was carried out on the online forum. Therefore, we will first explain some basic preconditions that the users need to adhere to when posting on The Space. Everything that is published on the forum is available to read for the public, but individuals who would like to post something must have an own account (free registration, without need for real identification). One person can have several different accounts or aliases, but it takes about three days from registration to being allowed to make postings. There are also several rules for publishing posts, which, if not being followed can lead to warnings or even temporary cutoff from the forum. One such rule, which complicated this specific crime-solving process, is that it is forbidden to look for or reveal information with the purpose of disclosing a user's identity. It is also not allowed to associate one username with other accounts on the forum or other websites. Hence, although the group knew that the offender was active on the forum, they could not use the forum itself to reveal his identity. They could, however, have discussions about the real person who made the pet killings and use various methods to come up with whom he or she was. Furthermore, the layout of the forum is rather simple, in that it is just a discussion thread where new comments are added in a long list. There are no possibilities to create sub-topics or sorting the posts, but a user can include a previous post to show whom the reply is directed. Also, assigned editors can delete posts that are considered to break the forum rules.

\section{Organizing the investigation}

In the analysis of the more than 8000 posts on The Space related to our case, we were able to point out several different roles, distributed over the hundreds of participants active during the six months' time we studied the process. More broadly we also classified these roles into three general functions: 1) operational functions, 2) managerial functions, and 3) noise. First, we would like to point out that the functions and the roles to some extent can be overlapping, and that a single user can take on various roles. We also need to highlight that although we could by the content of the posts suspect that some highly involved usernames are owned by the same person, we exclude such analysis since it would have required more qualitative inquiries to be sure.

The first category is what we call the operational functions, more precisely those users who contribute to the knowledge production of finding the perpetrator and thus solving the crime. This category included different roles, which jointly formed the distributed collaborative search group. There were, for instance, the initiators or idea generators, who took active roles in starting conversations about a specific topic, asking questions to the crowd, or suggesting new activities and methods. One initiator was naturally the user who started the thread in the first place. In this case, the user began by asked some general questions about the incident that he or she had heard about and read in the news and also adding a link to an article in the local newspaper.

Another typical example was when a photo of a handwritten letter from the alleged perpetrator was published by a user on the forum, and another user posted: "Does someone have the patience to transcribe this shit so it is possible to read it? I get a migraine when trying to see what the $\mathrm{fu}^{\star} \mathrm{k}$ it says." This post was followed by a massive collaborative work in trying to interpret the content of the letter. A second and quite common activity was hypothesis formulation, i.e., propositions about key things in the investigation such as who is the offender, what is the general motive, why did things happen as they did, etc. These profiling propositions were made based on available knowledge, previous experiences or just personal beliefs, and ranged from extremely substantiated claims to mere opinions or even blind accusations. These hypotheses formed possible paths for the search work, but they also acted as cues for that user's legitimacy and credibility within the community. A third important operational role was the information absorbers, who added information from the surrounding environment into the conversation on the forum. Sources for such information could, for instance, be other media (e.g., newspapers, Facebook, similar cases, laws and rules, etc.), but it could also be local information (e.g., incidents, facts, people, moods, etc.). The latter was possible because of the large amount of participating users who actually was from the geographical area of the crimes, and they functioned as local sensors, and also went to look for clues on the crime scenes. These activities are partly overlapping with the role of $a c$ tion interveners, who took own initiatives to not only report secondhand information but also to individually generate new information. Examples of such activities were, for instance, that users made phone calls to involved people or to the police, and afterward report the content of the online forum. They also mobilized night walks or public manifestations, and even tried to start conversations with the perpetrator. One illustrative post: 
I saw a guy on the tram toward [a district] that I also saw on yesterday's manifestation. He looked nervous and suddenly jumped off at [a tram station]. When you read this, send me a PM, so that I can count you off. You recognized me very well, I noticed.

Based on the result of all these different ways of information gathering, there were also crucial synthesizing functions, for summarizing and critically analyzing the content. The summarizing - to descriptively point out key milestones in a timeline or to provide a general progress report - was important especially because of the huge number of posts and that the Internet forum is not designed to help the users to structure or sort them by themselves. It helped newcomers and non-frequent users to be faster updated on the status of the work. The analyzing part included e.g., the generation of patterns of discussion threads and how different activities were linked to each other, as well as to other knowledge generated within the community.

The second category we highlight is the managerial functions. These activities aimed not to solve the crime in itself but rather to manage the huge information flow that happened on the forum. Hence, they took on more general facilitating roles where users bring in their leadership and organization skills for guiding and steering the progress or function as a catalyst for other participants' engagement. People in the thread made such facilitation attempts in various ways, from criticizing 'bad' behavior (e.g., "But please, it is enough with all the criminal profiling now. There are three walls of text with 'I believe the offender is a lone psychopath who lives with his mother and read Strindberg before going to sleep") to cheering (e.g., "Wake up thread! Perhaps you have seen a weird old man in a cap, or blood stains? Come on! We need you!') and promoting 'good' behavior by concurring with a previous speaker. Much of this facilitating amongst users was made in a quite tough and 'macho' manner, such as " $F u^{\star} k i n g$ idiots in this thread. Damn, your line of thoughts is so pathetic that you could as well shut up," followed by a long exposition about what was wrong in their analyses. It is also important to point out that leadership and influence of a user within this case are not necessarily associated with the frequency of posts being made by that specific user. The user who published, by far, the most posts in the thread (over 350 posts) came to have a marginal impact. Instead, other users started to criticize him for publishing too many irrelevant things, and thus diverting the attention and creating too much noise. In fact, one important managerial function was to critically question other users' credibility to weed out wrong or misleading information. One example to illustrate this can be seen in this post:

I have tried to have a reasonable discussion with [user] but have reached the conclusion that it only leads to more questions and confusion than answers and clarity. I will not waste time on TROLLs. I have good knowledge about the geographical area, and when I asked about detailed descriptions about the surrounding, I just received smokescreens and boloney.

The third category we will point out is the noise, and that would arguably be the least productive feature for generativity. Noise includes nonsense texts, just random speculations, or even unsocial or rude behavior. These acts are in the online vocabulary called trolling. Trolling is when a user repeatedly and deliberately breaches the rules of the forum just for the aim of provocation or to lead the discussion off topic. Such behavior happened a lot in the discussion forum, and was most likely spurred by the fact that the users write anonymously. A typical example is for instance after one user had published a map where key incidences had taken place, another user replied: "You have made a fantastic map. Too bad that it does not mark out locations for chanterelles." Also, a lot of racist comments were posted, speculating in the color of the skin of the perpetrator or just pointing out an alleged overrepresentation of immigrant criminals. When being too far off the topic these posts were removed by the editors, but to a large extent, they were allowed to continue.

Another vocabulary used on online forums is necroposting, which is a message that is posted as new but is just a repetition of previous old discussions. Many of these double-postings happened because of the difficulties for users to get an overview of what previously had been posted, especially when the discussion grew with a rapid pace. Hence, it was often done by the users unintentionally. A typical post to illustrate this: "Perhaps this has been posted earlier, but I anyway through away this link: HTTP://..." Several comments pointed out how negative this 'noise' is for the generativity of the community, and its ability to solve the crime. For instance, one user wrote "this thread is definitely starting to lose its earlier power with all the nonsense going on," and another user stated: "I am sorry, but I have not found the strength to read through one billion posts yet..."

However, although it is rather easy to understand the frustration from some users who felt it was an inefficient design of the forum and timeconsuming to keep up with the latest developments, it is also worth to point out two things about this noise. First, as users and editors, it is difficult in the making to separate the noise from important information. Secondly, and related, it is impossible to predict which posts will generate other productive ideas and information further down the line. As an example, for sure one of the groups acting on The Space helped the police with significant knowledge to capture the offender, but there were simultaneously several other groups that also were working on the case but with different paths, which only afterward proved wrong and misleading. As one of the users from this group pointed out in a post;

I also believe that it is better if many people run after the same ball, it creates redundancy, which is a comfort. It is a strength and security in that that many engage themselves and act. I am glad that we had the luck to work with a trace that proved correct, but there were many other interesting ideas to work with $[\ldots]$ It is perhaps similar to evolution, that many different approaches, and some luck, guaranteeing that at least one life form survives. Diversity in ideas and approaches is a strength that increases the likelihood that someone will reach the target. 


\section{Opportunities and challenges with generative Internet forums}

The case about the crime solvers on The Space has illustrated a new form of voluntary participation, organized anonymously online and with no hierarchical structure or extrinsic reward mechanisms at play. Much resemblance can, as pointed out, be found with commons-based peer production in the sense that the modes of organizing are radically decentralized and collaborative, based on loose and voluntaristic ties (Benkler, 2006). The work is modular with fine granularity and low-cost integration (Benkler \& Nissenbaum, 2006) in the sense that any participant can add to the discussion with whatever content he or she wishes, either by starting new threads or replying on previous comments. This uncontrolled coordination is similar to what Burgess and Green (2013) found in their study on the YouTube community, portraying it as an aggregation of many subgroups, each with their specific practices and purposes, sometimes even at odds with the other groups on the website. Hence, they showed that online communities are far from a single collective, which also resembles the organizing on The Space.

Due to the critical mass of active users on The Space, the discussions tend to generate massive activities, and the participants join with different knowledge and resources at hand. A diversity of roles and viewpoints can produce highly generative processes where ideas are created, challenged and remixed in a rapid tempo (Zittrain, 2008). The organizing on Internet forums such as The Space utilizes voluntaristic cognitive surplus (Shirky, 2010) of time and energy which on an aggregated level is providing almost non-exhaustible resources. This large crowd includes ordinary people but also individuals with strong analytical capabilities, experts on specific crime-solving knowledge domains, and people with detailed local knowledge. A concrete result of this abundance of resources is that it is for the community possible to have a vast number of parallel hypotheses and mini-projects open at the same time and that this redundancy of information increases the likelihood that at least one of the paths will have productive outcomes. Compared to normal policing, the amount of work-hours available for the specific task is higher, but arguably also the range of expertise is more elaborated within the large crowd, in comparison to a small police task force. In other words, voluntaristic collaborations for solving crimes online have shown benefits in the case of The Space, both regarding the breadth and depth of enrolled investigation activities.

This exponentially additive knowledge-flow among a distributed and fluid network of diverse individuals is arguably the core mechanism in the pet mystery solving. The online forum on The Space would technically be considered generative in Zittrain's terms, due to its possibilities to leveraging discussions in many different topics simultaneously and the low barriers to entry for non-experts (Zittrain, 2008). The generativity is enhanced because all the participants are anonymous, and that the forum encourages freedom of speech. The anonymity contributed to the creative approaches in the search for the offender, since the users were not bound to laws, nor social and ethical conducts, in contrast to the National Police force or public organizations. It was, for instance, possible to continuously reveal identities of potential suspects to the crowd and to make traps and take other private initiatives without asking for permission from higher authorities. Compared to regular police work, the online participation on The Space, hence, were not bound to as many restrictions and limitations - ethical as well as practical - that the regular police force faces.

However, the technological infrastructure was also considered by many participants to lack a user-friendly design, which made it hard to get overviews of the different discussion threads. Other studies have suggested that technologies can help users in e.g., filtering, sorting, recommending and crediting contributions to enhance production (De Alfaro et al., 2011), but for The Space, technology acted as a general platform for generativity but not as a direct facilitator. Instead, participants had to develop specific organizing mechanisms to sort out the helpful information from the noise. So although there were no hierarchical structures or formal role descriptions, the crimesolving on The Space was highly organized from the viewpoint that certain roles and functions as well as emerged norms and routines informally and fluidly governed the progress. Therefore, we enforce the notion of organizing generativity as a key driver for solving the case through CBPP modes of production.

It has been pointed out in research that users on online forums tend to take on specific roles by enacting consistent and systematic behaviors that serve a particular function (Baym, 2010), such as local experts, answering people, conversationalists, fans, discussion artists, flame warriors, trolls. In the analysis of the solvers on The Space, we found similar roles, and we aggregated them into three general functions - operational, managerial and noise - which are all intertwined and together make up important bases for organizing generativity. The various operational roles work together in a somewhat chaotic, unstructured and highly decentralized production flow. Here, the creative generation of hypotheses was followed by testing and analyses, leading to new hypotheses in an ongoing iterative process. Profiling work was fine-tuned among the users, ideas and arguments were supported or criticized, and the collaborative discussions leveraged the motivated crowd to release their co-creative efforts. The operational function shows resemblance with the findings of Bennett et al. (2014) in their study on crowd organization in civic protest manifestations, where they suggest three mechanisms for peer production: production (i.e., creating and publishing content), curation (i.e., preservation, maintenance and sorting of digital assets) and dynamic integration (i.e., enabling switching between different actors, networks, platforms or technologies). The operational function on The Space was backed up by managerial functions and escalated through the redundancy of noise and nonsense that inspired structuring and ordering and as well as creativity in action. Hence, trolling and noise should not only be considered as problematic for the generative process, but if managed well can they also be seen as a prerequisite for escalating the productive flow. At the same time, the huge number of posts on The Space filled the discussion thread with much nonsense, and as the online forum has a rather non-user friendly design, it becomes a substantial investment to engage oneself in the progress. This is why managerial functions become so critical for organizing the generative activities, and also to instill the commitment and engagement from the users. 
Fig. 1: Three functions for organizing generativity in CBPP online collaborations

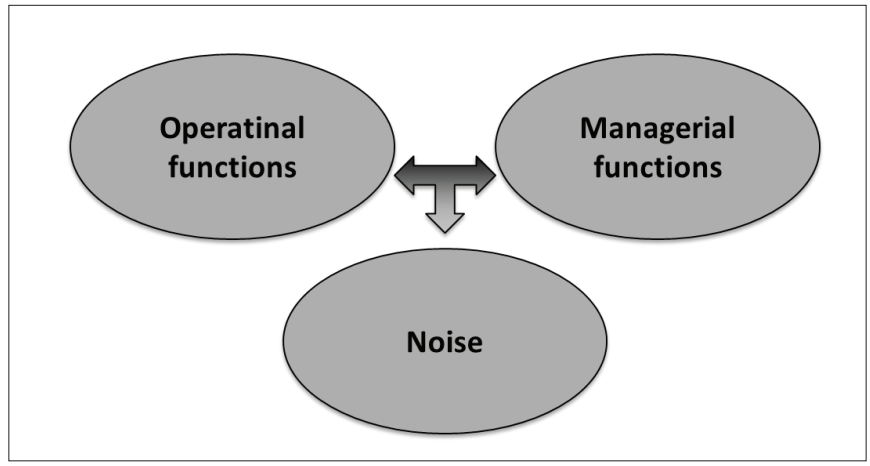

In viewing the process as a CBPP with highly generative features (organizing rather than technological), it aids the analyst in the understanding of the power of such distributed and additive processes. As already pointed out (e.g., von Hippel \& von Krogh, 2006; Poor, 2014), the motivational mechanisms for peer-to-peer contributions vary from intrinsic to extrinsic drives, but since the participation on The Space is anonymous, the extrinsic motivators are highly limited. Instead, just the quest to find the offender, to solve a complex puzzle, to understand what happened, seemed more than enough a stimulus to engage the large crowd in generating positive feedback-loops. These incentives and the creative progress would thus be linked more to the value creation of sensemaking than to the value creation of monetary rewards (Bechmann \& Lomborg, 2013).

CBPP and generativity are too often associated with positive outcomes such as increased creativity, efficiency or effectiveness (Kreiss et al., 2011). Our case also reveals the problems and challenges involved with such anonymous and uncontrollable ventures. As Baym (2010) puts it:

Media with fewer social cues often trigger hopes that people will become more equal and more valued for their minds than their social identities, but also raise fears that interactions, identities, and relationships will become increasingly shallow, untrustworthy and inadequate. (Baym, 2010)

Similarly, Nielsen (2014) found in a study on online comments on newspaper websites that the anonymity of commenters tend to downgrade their real impact on journalists' engagement with readers. Anonymity can thus lead to reduced interconnectedness and increased awkward social behavior among users (Baym, 2010). Also on The Space, the language can be rough, with much curses and personal attacks, and this flaming culture (Lea et al., 1992) possibly also excludes several potential contributors from joining the collaborative work. It is a well-known fact that so-called 'lurking' is a common practice in online forums (Schneider et al., 2013), that is, users who follow discussions passively. Preece et al. (2004) found that one of the most common reasons why people 'lurk' rather than contribute is that they do not appreciate the group dynamics or because they fear aggressive responses. Arguably, the ethical aspects of the publishing on online forums are often overlooked, with frequent occurrences of false personal accusations, bullying and other forms of defamation coming from the anonymous crowd.
Hence, the 'open' climate may lead to creativity and productive, nonorthodox solutions, but the lack of control mechanisms and regulations may also feed hostile and destructive environments (Kreiss et al., 2011). This raises an even more fundamental question, whether these citizen collaborations should be encouraged as a complement or even replacement to ordinary police work. Naturally, it is impossible for the State to stop these types of public initiatives, especially since The Space locates their servers outside of the national borders, but it is anyway important to critically reflect on their legitimacy in the public discourse by examining both the positive and negative potentials. In this specific case, it became even more complicated, since the offender turned out to be an active participator on the forum. A suspicion can be raised that the attention he received triggered him into continuing his pet-slaughtering in order to see the reactions of the crowd. In other words, yes, The Space community collectively helped the police to arrest the offender, but the forum itself might also have escalated the crimes in the first place.

\section{Conclusion}

In this paper, we have drawn upon the theoretical concepts of CBPP and organizing generativity to analyze online citizen collaborations. A case study was applied, illustrating how users on The Space organized themselves to find and expose a pet killer, and to help the police in bringing him to justice. Although a case study may be seen as having limited generalizability for the overall population of online engagement, we argue that our findings have important empirical and theoretical contributions.

First, we provide a detailed empirical account on online citizen collaboration, which is an increasingly important phenomenon in contemporary society but has so far only sparsely been addressed in academic literature. We illustrate in depth the complex organizing mechanisms that take place in these new organizational forms and discuss both their potential benefits and challenges.

Second, we proclaim that CBPP is a useful theoretical concept for analyzing such online citizen collaborations and point specifically to the organizing generativity as a key driver for shared problem solving and value creation. CBPP has mainly been used in the domain of open source literature, and we argue that online citizen collaborations in some vital respects differ from such projects. The interplay between the anonymous crowd of private investigators, the public authority of the National Police force, and the traditional media makes the practice of CBPP more delicate as it exposes the positive but also the negative aspects of 'freedom' and lack of control in the public discourse. The generative process also involves much more 'noise' than in open source projects, as the barriers to entry the conversation are very low (e.g., you do not need to know how to code). In a sense, online citizen collaborations can be seen as even more 'pure' CBPP than open source, as they are more inclusive, decentralized and unstructured.

Third, in the analysis of The Space, we open the black box of CBPP to discuss how it is organized in practice. Three general functions are introduced - operational, managerial and noise - which are all 
intertwined and together make up important bases for organizing generativity. The case shows that, in order to cope with the abundant information or 'noise', various managerial functions emerge to level up the distributed operational activities. These organizational functions are in this specific case arguably also more important for generativity than the rather non-user friendly technological infrastructure. Put differently, we suggest that it is not enough to analyze the characteristics of information technologies to study distributed coordination and the enhancement of intrinsic motivation and engagement of a large crowd per se, but we need to also put it into a social, political, juridical and ethical context. Our study also raises important questions for future research, to further advance our understanding of new organizational forms facilitated by new media and new societal values, and to critically examine and discuss their legitimacy and merits in an increasingly open society.

\section{Biographical notes:}

Dr Björn Remneland Wikhamn is an associate professor and lecturer in organizational theory and innovation management at the School of Business, Economics and Law, University of Gothenburg. His research interests include innovation practices and network organizing.

Dr. Jan Ljungberg is Professor in informatics at the Department of Applied IT, University of Gothenburg. His research interests include, among others, innovation, social media, and open source.

Dr. Bertil Rolandsson is an associate professor at the Department of Sociology and Work Science, University of Gothenburg. His research focuses on ICT and the organization of work, and issues such as governance and trust.

Dr. Magnus Bergquist is professor in informatics at Halmstad University. His interests include among others, innovation, open source and governance.

\section{References}

Baker, T., \& Nelson, R. E. (2005). Creating Something from Nothing: Resource Construction through Entrepreneurial Bricolage. Administrative Science Quarterly, 50(3), 329-366.

Baym, N. (2010). Personal Connections in the Digital Age. Cambridge. Malden, MA: Polity Press.

Bechmann, A., \& Lomborg, S. (2013). Mapping actor roles in social media: Different perspectives on value creation in theories of user participation. New Media \& Society, 15(5), 765-781.

Benkler, Y. (2006). The Wealth of Networks: How Social Production Transforms Markets and Freedom. New Haven: Yale University Press.

Benkler, Y. (2013). Peer Production and Cooperation. In J. Bauer \& M. Latzer (Eds.), Handbook of the Economics of the Inernet (pp. 91119). Cheltenham and Northampton: Edward Elgar.

Benkler, Y., \& Nissenbaum, H. (2006). Commons-based Peer Production and Virtue. Journal of Political Philosophy, 14(4), 394-419.
Bennett, W.L., Segerberg, A., \& Walker, S. (2014). Organization in the crowd: peer production in large-scale networked protests. Information, Communication \& Society, 17(2), 232-260.

Burgess, J., \& Green, J. (2013). YouTube: Online video and participatory culture. Cambridge, Malden: John Wiley \& Sons.

Chesbrough, H. (2003). Open Innovation: The New Imperative for Creating and Profiting from Technology. Boston, Mass.: Harvard Business School Press.

Cogburn, D. L., \& Espinoza-Vasquez, F. K. (2011). From networked nominee to networked nation: Examining the impact of Web 2.0 and social media on political participation and civic engagement in the 2008 Obama campaign. Journal of Political Marketing, 10(1-2), 189-213.

De Alfaro, L., Kulshreshtha, A., Pye, I., et al. (2011). Reputation systems for open collaboration. Communications of the ACM, 54(8), 81-87.

Goldsmith, S. (2010). The power of social innovation: How civic entrepreneurs ignite community networks for good. San Francisco: Jossey-Bass.

Goldsmith, S. \& Eggers, W. D. (2005). Governing by network: The new shape of the public sector. Washington: Brookings Institution Press.

Hertel, G., Niedner, S., \& Herrmann, S. (2003). Motivation of Software Developers in Open Source Projects; An Internet-Based Survey of Contributors to the Linux Kernel. Research Policy, 32(7), 1159-1177.

Jenkins, H. (2006). Convergence culture: Where old and new media collide. New York: New York University Press.

Kozinets, R. (2010). Netnography: Doing Ethnographic Research Online. London: Sage Publications.

Kreiss, D., Finn, M., \& Turner, F. (2011). The limits of peer production: Some reminders from Max Weber for the network society. New Media \& Society, 13(2), 243-259.

Lea, M., O'Shea, T., Fung, P, et al. (1992). 'Flaming' in computer-mediated communication: Observations, explanations, implications. In M. Lea, (Ed.), Contexts of computer-mediated communication (pp. 89112). London: Harvester Wheatsheaf.

Leonardi, P. M. (2011). When flexible routines meet flexible technologies: Affordance, constraint, and the imbrication of human and material agencies. MIS Quarterly, 35(1), 147-167.

Loveland, J., \& Reagle, J. (2013). Wikipedia and encyclopedic production. New Media \& Society, 15(8), 1294-1311.

Mercea, D. (2012). Digital prefigurative participation: The entwinement of online communication and offline participation in protest events. New Media \& Society, 14(1), 153-169.

Mowery, D.C. (2009). Plus ca change: Industrial R\&D in the "third industrial revolution". Industrial and corporate change, 18(1), 1-50. 
Nielsen, C.E. (2014). Coproduction or cohabitation: Are anonymous online comments on newspaper websites shaping news content? New Media \& Society, 16(3), 470-487.

O’Mahony, S., \& Ferraro, F. (2007). The emergence of governance in an open source community. Academy of Management Journal, 50(5), 1079-1106.

O'Mahony, S. (2003). Guarding the Commons: How Community Managed Software Projects Protect Their Work. Research Policy, 32(7), 1179-1198.

Poor, N. (2014). Computer game modders' motivations and sense of community: A mixed-methods approach. New Media \& Society, 16(8), 1249-1267.

Preece, J., Nonnecke, B., \& Andrews, D. (2004). The top five reasons for lurking: improving community experiences for everyone. Computers in human behavior, 20(2), 201-223.

Schneider, A., von Krogh, G., \& Jäger, P. (2013). "What's coming next?" Epistemic curiosity and lurking behavior in online communities. Computers in human behavior, 29(1), 293-303.

Shirky, C. (2010). Cognitive surplus: Creativity and generosity in a connected age. New York: The Penguin Press.

Siggelkow, N. (2007). Persuasion with case studies. Academy of Management Journal, 50(1), 20-24.

Stake, R. (2000). Case Studies. In N. Denzin \& Y. Lincoln (Eds.), Handbook of Qualitative Research (pp. 435-454). Thousand Oaks, CA: Sage.
Strauss, A., \& Corbin, J. M. (1990). Basics of qualitative research: Grounded theory procedures and techniques. Thousand Oaks: Sage.

Walther, J. B. (2002). Research ethics in Internet-enabled research: Human subjects issues and methodological myopia. Ethics and Information Technology, 4(3), 205-216.

Weiss, M., \& Gangadharan, G.R. (2010). Modeling the mashup ecosystem: structure and growth. R\&D Management, 40(1), 40-49.

West, J., \& O’Mahony, S. (2008). The role of participation architecture in growing sponsored open source communities. Industry \& Innovation, 15(2), 145-168.

von Hippel, E., \& von Krogh, G. (2003). Open Source Software and the "Private-Collective" Innovation Model: Issues for Organizational Science. Organizational Science, 14(2), 209-223.

von Hippel, E., \& von Krogh, G. (2006). Free Revealing and the Private-Collective Model for Innovation Incentives. R\&D Management, 36(3), 295-306.

Wright, S. (2012). Politics as usual? Revolution, normalization and a new agenda for online deliberation. New Media \& Society, 14(2), 244-261.

Yates, D., \& Paquette, S. (2011). Emergency knowledge management and social media technologies: A case study of the 2010 Haitian earthquake. International Journal of Information Management, 31(1), 6-13.

Zittrain, J. (2008). The Future of the Internet And How to Stop it. New Haven, CT: Yale University Press. 
